\title{
Chapter 3 Agricultural Markets
}

Since the times of Adam Smith, ten thousands of economists have devoted most of their efforts to understanding markets. The resulting narrative they have helped develop impressively explains a large number of real-world phenomena.

The most basic version of this narrative goes as follows: Two selfish individuals find that they can increase their utility by trading with each other. They engage in the trade on a fully informed base and end up happier than they were before.

Economists also acknowledged that life can be somewhat more complex than that and have developed their models accordingly. For example, they modelled cases where full information was not available to one or both of the market partners. All these extensions of the basic model have led to a large body of thought about exchanges. Millions of pages have been filled to adapt the two selfish individuals to the linkages and insecurities in the real world.

In this chapter, we will examine three market-related fields of decision-making in the realms of agriculture and rural areas. We start by coming back to the issue of occupational choice, this time mainly from a market perspective. A second section will then focus on the dynamics of settling or depopulating rural areas from a market perspective. Finally, we will look at choices on the food market.

\subsection{Occupational Choices}

The chapter on hierarchies (Chap. 2) already reflected on the issue of occupational choice. However, few other decisions have such a strong and lasting effect on the course of our lives as the choice which professional path to follow. Moreover, few other decisions are as important for the scope of agriculture as we know it today.

We therefore will broaden the reflection on occupational choice by two aspects. First, we will analyse how a young person decides whether to enter the parents' farm. However, farm work is not necessarily a lifetime decision, nor does it mean to take over a farm. Therefore, we will look at motivations for employed and temporary farm 


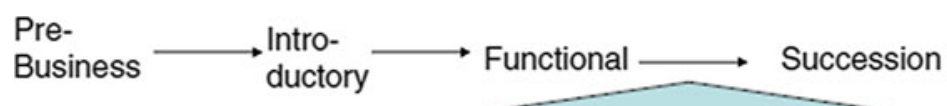

Environment-related factors

\section{identity-related factors}

Fig. 3.1 The process of occupational choice (Mann 2007a: 437)

work in a second step. The insights we gain will result —once again-in a theoretical model.

\subsubsection{Identity and Environment}

When modelling the process of occupational choice in the previous chapter, we took a rather abstract 'economic' approach. We assumed a preference for or against becoming a farmer among the potential successors, instead of concluding such preference from an analysis. In fact, economists tend to assume preferences as given and leave it to psychologists to focus on the genesis of preferences.

One of the most thorough empirical analyses of the complex interplay between parents' expectations and their children's ambitions, of the roles of gender and personal character, was done 20 years ago in New Zealand by Keating and Little (2007). They found that 'parents are less aware of the messages they are sending to their children than are the children themselves' (p. 167). Parents define their choice, or recommendation, based on gender, health and abilities.

It is important to note that the process of succession has several phases and that each phase has different driving factors. Psychologists emphasize that adolescence is the phase of identity generation. Youth is a time in which longer-lasting preferences and abilities have to be defined. More often than not, the passage from adolescence to early adulthood then involves the individual adjusting to the environment. The 'storm and stress' years of identity craving are followed by self-establishment and adaptation.

All of these factors result in a theoretical model of farm succession as depicted in Fig. 3.1. Identity-related factors in the farm succession process are a liking for working outside, for working with animals or for working self-employed. Environment-related factors are the farm's potential to generate income, the prospects of agricultural subsidies or tax laws. Along the different phases of the succession process, it is likely that environment-related factors gradually become more important, whereas the role of identity-related factors decreases over time.

Some years ago, a quantitative study from Switzerland (Mann 2007a) tested and partly confirmed this model. Seven hundred and thirty-one children of farm managers aged between 14 and 35 years returned a questionnaire on their intention to take over the parental farm. The responses showed that agreement with sentences like 'I like 
working outside' decreased in their predictive power with increasing age. However, although the importance of environment-related factors could be shown, it was not possible to verify empirically that their impact increased with increasing age.

One fringe result of the study referred to the gender aspect (Mann 2007a). The farm managers' daughters did not only respond in fewer numbers than the sons did, they also showed much less inclination to take over their parents' farm. The interpretation of this finding is left to the reader: Are women intrinsically less interested in farming than men are, or did the parents' behaviour hold daughters back from becoming engaged in agricultural affairs?

\subsubsection{Part-Time Farming}

Part-time farming is an arbitrary term. If the farmer's spouse earns a few Euros per year by helping in the church, will the farm be considered a part-time farm? Or does this term require a farm manager who earns at least $50 \%$ of the income off-farm?

Off-farm income is much easier to define than part-time farming. Furthermore, one of the certain long-term tendencies in worldwide agriculture is the rising share of off-farm income. In the US, nowadays $90 \%$ of the total income of farm households comes from sources outside agriculture (Briggemann 2011).

This trend means, of course, that one of the presumptions in the previous subsection was misleading if not false. Becoming a farmer is not really a binary decision. For example, if you are unsure whether to become a teacher or farmer, you have the option of becoming both. Many social scientists in the past thought that part-time farming would merely be an intermediate stage during a family's phasing out of agriculture. At least for the short and medium terms, this view could not be confirmed. Empirical studies (e.g. Kimhi 2000) have shown that off-farm income may even stabilize the persistence of farms.

Nonetheless, disadvantages of part-time farming exist. At least in countries with small farms, such as Switzerland, part-time farms and other small-sized farms suffer from missing economies of scale and therefore low degrees of productivity (Mann 2007b). The economic disadvantages of part-time farming were also demonstrated for Norway: Mittenzwei and Mann (2017) found that incomes of households with $100 \%$ farm income or $100 \%$ non-farm income exceed the income of households with shared incomes.

Despite these economic aspects, there may be good arguments for pursuing a part-time strategy. Tzouramani et al. (2014), for example, showed that Greek farmers enter off-farm activities to buffer their risk. Work satisfaction may also play a role: Carrying out rather specialized and monotonous tasks is less satisfying than being engaged in a broad range of activities, in agriculture and beyond (Besser and Mann 2015). Thus, a trade-off between monetary and non-monetary utility may exist, a thought that we will address later in this chapter.

Such trade-off certainly applies to the $5 \%$ of Swiss farms that generate a negative agricultural income, which the farmers usually compensate by a positive (and often 
generous) off-farm income (Mann 2015a, b). These farmers choose to manage their farm for non-financial reasons. The lines between work and leisure are certainly blurring in such cases.

\subsubsection{Employed on a Farm}

We have focused so far on the decision to become the manager on a family (full-time or part-time) farm. While this is a decision that 500 million active farm managers (this is the number of family farms as estimated by Lowder et al. 2016) have made at some stage in their lives, an even larger number of persons have made the decision to be hired on a farm, a group that this book so far has neglected. Two important differences between the two groups are immediately obvious:

- Farm work as an employee is a much shorter-term decision than becoming a farm manager, even in countries in which becoming a farm manager is often not a lifetime issue. Farm workers are often hired for months, weeks or even days.

- Although the literature is ambiguous on the merits of becoming a farm manager, social scientists do not draw a beautiful picture of the conditions and lives of farm workers. Being a farm worker is often considered as a precarious occupation.

This latter point can be illustrated from a historical and from a systematic perspective. To start with the former, the history of slavery in the US is a very visible case for showing how the least-privileged people-African Americans-mostly ended up as farm workers. Even in 1900, decades after the abolishment of slavery, more than half of all farm workers were still African Americans (Perry et al. 2014). Now as then in most societies, immigrants are still the people living under precarious conditions, and they provide a lot of the workforce of major farms in wealthy countries, be it Mexicans in the US, Romanians in Germany or Moroccans in Spain. Repeatedly, riots break out, as Corrado et al. (2017) showed in an international record.

Generally, one says that although farm managers have to work hard for an income that is on average rather low, they enjoy a great degree of freedom and still have the chance to make a lot of money on the volatile agricultural markets. Farm workers do not share these advantages. By receiving low payments (Zhao 1999) and carrying out monotonous work delegated by their managers (Pierson 1978), they do not participate in the bright sides of farming.

This situation implies a great need for unions to represent the interests of this vulnerable segment of the workforce. Paradoxically, the degree of organization among farm workers is extremely low. Saverio Caruso (2016: 277) explains: 'Among the key reasons for labourers' weak position in relation to their employers are the predominant seasonal and informal nature of labour relations, the lack of direct links between workers and employers, and, consequently, the difficulty in organizing collective bargaining mechanisms.' 


\subsubsection{Alpine Summers}

In the previous subsection, we described an environment in which labour is hard, workdays are long and payment is low. Could it possibly get worse? What if the labour market existed for only three months? What if you knew beforehand that you have to look for another job to cover the remaining nine months of the year? What if - to make things worse-housing and consumption choices were particularly basic?

This is what happens on Alpine summer farms. Nevertheless, between 30,000 and 50,000 people work there each year, and most of them would have other opportunities; in fact, some of them even leave well-paid jobs with banks or consultancies to enter Alpine summer farming.

For readers less familiar with the habits in Europe's largest mountain area, we will outline the basics of this peculiar labour market: Around one million hectares of mountainous grassland are covered by snow for a good time of the year. However, in the time between June and early September, grass grows that can be utilized for grazing. Therefore, farmers in the region often choose to send their cattle, their sheep or (occasionally) their goats to summer farms where other people watch their animals, herd them and milk them. This custom saves the farmers not only feedstock but also labour that can be used on their land.

Part of the Alpine summer farms are run by single farmers, others by cooperatives or local authorities. In any case, they usually hire staff for which they provide some basic housing in the middle of nowhere. Accessibility varies, and in many places, food is brought from the lowlands just once a week.

A Swiss-Italian researcher (Calabrese et al. 2012, 2014) visited 50 Alpine summer farms in Switzerland and interviewed 120 workers to understand the underlying motivations. A cluster analysis showed that the workers could be categorized in four groups:

- 'Tourist workers' were the group matching the understanding of labour markets in which one primarily worked to make a living. This group was mostly composed of male foreigners, who viewed low salaries in Switzerland as being not too bad by international standards. While these workers often reported conflicts with their employers, they appreciated contacts with tourists on the summer farm.

- The situation was completely different for the 'eremites', who worked on Alpine farms to get away from everything and enjoy the solitude. They usually had a non-agricultural background and mostly were faithful workers, likely to attend training beforehand and to return to their summer farm in the next year.

- For the 'nature lovers', the motivation for entering the experience was not so much the longing for solitude but the appreciation of the landscape, nature and animals. This aspect turned out to be not the best motivator for this kind of job: Nature lovers were likely to come into conflict with their colleagues and to leave Alpine farming behind as a one-time experience.

- By far the oldest age group were the so-called 'traditionalists', for whom coming to the summer farm was a fixed part of their yearly routine. They considered Alpine farming as a duty and complained about their inexperienced colleagues. Usually, 
they were male and Swiss, and often they managed the summer farm jointly with their family.

For employers, it is inconvenient if a new team arrives every summer requiring them repeatedly to explain all work steps. As everybody wishes the workers to return in the next year, Calabrese et al. (2014) carried out a regression analysis to identify both financial and non-monetary factors with a predictive power for the employee's intention to return in the next year.

It sometimes can be illuminative if certain variables do not have any explanatory power. This was the case for all financial variables involved. Employees were asked whether they found their wage level satisfactory, they were asked about their wage level, and, dependent on education and experience, their wage was compared with a wage that could have been expected. None of these three variables did have any predictive power for the intention to return to the farm in the next year. Apparently, money is not the key motivator for Alpine farming.

Two other factors were much more helpful in explaining decision-making. One of them was infrastructure. It mattered, for example, whether the living quarter had a heating system. Being cold at night made a worker much less likely to return to the place thereafter. The other factor was conflict, be it with the employer or in the team. Rude remarks and arguments apparently were no good ingredients for a rich experience in the Alps.

\subsubsection{The Activity Choice Model}

Economic science has occasionally been criticized for a biased view on labour, which often is reduced to its money-generating function although it is only one side of the coin. Pagano (1985: 173) summarized this shortcoming with the following simple claim:

Conservative priests used to prescribe the status quo by saying that life itself was a means to a superior end existing somewhere in the sky; economists would assume a similar role by maintaining that working life is simply a means to a superior end, existing somewhere on earth, called consumption goods and leisure. But our working life affects our welfare as much as our non-working life and the availability of consumption goods.

The model by Rosen (1986) as outlined in Chap. 2 at least acknowledged that two important aspects influence the process of occupational choice: money and nonmonetary utility. The empirical evidence presented in the last two subsections underlined this notion, adding two important insights:

- Occupational choice may be, but rarely is, a once-in-a-lifetime decision. Although we still face a large degree of path-dependency in our careers, more and more people have to decide what to do next more than once in their lives. Therefore, the category of occupational choice should be supplemented with the category of activity choice. Activity choice would allow me some time of 'work \& travel' on a 


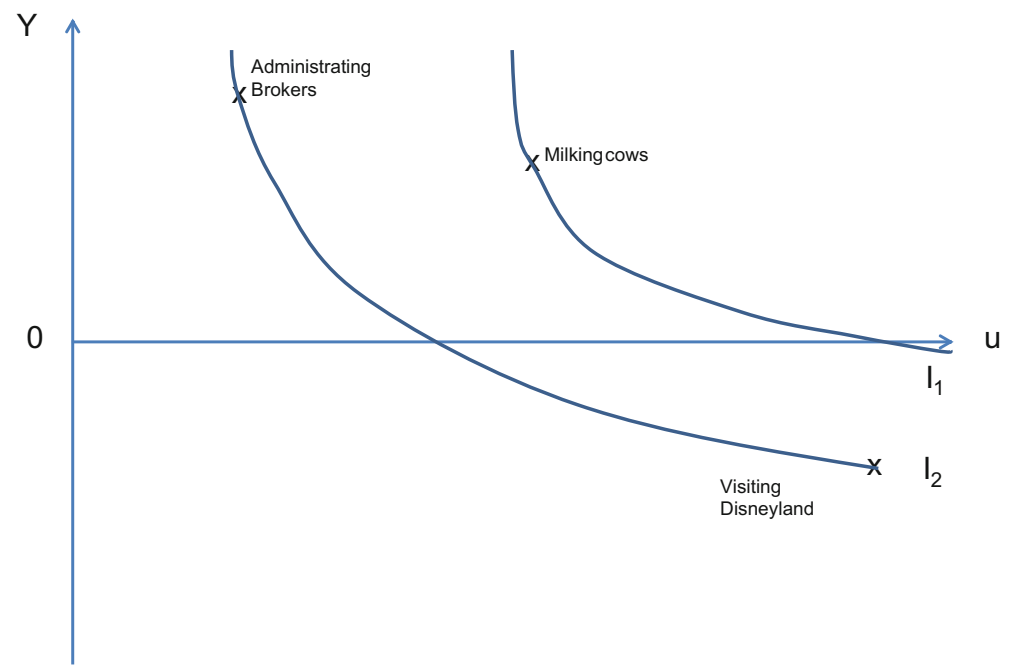

Fig. 3.2 The activity choice model

Canadian farm and a later job as a university teacher in Switzerland, which I then may interrupt by a summer of Alpine farming.

- The trade-offs between earnings and non-monetary utility may vary considerably. The case of Alpine summer farming demonstrates instances when the monetary component exists but shrinks in comparison with non-monetary utility components.

All these considerations lead to the 'activity choice model' as depicted in Fig. 3.2. It acknowledges that every activity has a monetary component as represented along the y-axis. An activity (such as chatting with my neighbour) may involve no money exchange so that it would be situated on the $\mathrm{u}$-axis where $\mathrm{y}=0$. Other activities with $\mathrm{y}<0$ (going shopping, eating out) are typically allotted to consumption, whereas activities with $\mathrm{y}>0$ are usually considered as work.

The u-dimension describes the non-monetary utility of an activity. Boring or even disgusting activities will be situated on the left side, and the curves shift to the right as occupations become more interesting and attractive.

The person considered in Fig. 3.2 can choose between three alternatives at a certain point of time: Administrating brokers is apparently an unattractive activity but generates a high income. Milking cows seems to generate more enjoyment but less financial return. The most non-monetary utility can be generated by visiting Disneyland, but this activity is linked to spending money.

For a rational choice between these three options, an additional piece of information is needed: the relationship with which the person in the model trades non-monetary utility against money. As usual in the world of microeconomics, this relationship is illustrated by a set of two indifference curves. As people favour a lot 
of money and fun over little money and fun, indifference curves on the upper right are preferred to indifference curves on the lower left so that

$$
\mathrm{u}\left(\mathrm{I}_{1}\right)>\mathrm{u}\left(\mathrm{I}_{2}\right)
$$

Translated back into practical terms, this equation implies that the individual would prefer milking cows for a small income to both working as a broker with a higher wage and visiting Disneyland with a higher fun factor.

In general, the activity choice model is a convenient tool to demonstrate how activities with low monetary returns can be a perfectly rational choice. It has been used as an argument against a minimum wage in which activities in the range minimally above the u-axis (i.e. with a low, but positive hourly return) are outlawed (Mann 2014a).

In the realm of agriculture, the activity choice model also has been used to illustrate the dual way in which external crises affect agricultural structures. Sadly, Australian agriculture could serve as a convenient example, because the country's farmers have faced many crises: In the early 21st century, many years of severe drought made large areas of land completely unproductive for years. Nevertheless, some regions were also affected by temporary flooding. Furthermore, Australia has hardly any protective measures such as tariffs on its borders. Thus, economically, farmers face the whole range of price volatility present on the world market, meaning that prices for their products went far down on several occasions.

Shaped by culture and by necessity, Australian farmers are among the most flexible in the world. Different to, for example, their European colleagues, they are usually ready to sell their farm and buy another or change to an entirely different occupation. On that base, the framework in the previous chapter would suggest that it was likely that crises such as drought, flooding or price drops would reduce the profitability of farming and therefore make it more likely that farmers opt out.

Coming back to the activity choice model, the model structure suggests that our view of the Australian circumstances may have neglected a second dimension, the dimension of work satisfaction. When crops stop growing, cows die of thirst, fields are flooded before harvest or when wool prices collapse, how will such circumstances affect the joy of managing a farm? If I am not able to successfully raise animals and grow corn, can I stay happy as a farmer? Will crises make it less likely that I carry on farming even if I ignore the economic aspect?

Structural equation models are a good tool to check for such complex interrelations because variables can be both cause and effect in a system. A structural equation model as depicted in Fig. 3.3 verified the two main drivers causing structural change: happiness and profitability. Although crises affect happiness and profitability more or less equally, happiness seems to surpass profitability in its effect on planned farm exits.

Summarizing, occupational choices always have an economic and a cultural, identity-related component. Both are worth studying. We presume that this interplay of economic and psychological factors for decision-making also exists in other areas where decisions have to be made. Let us examine them. 


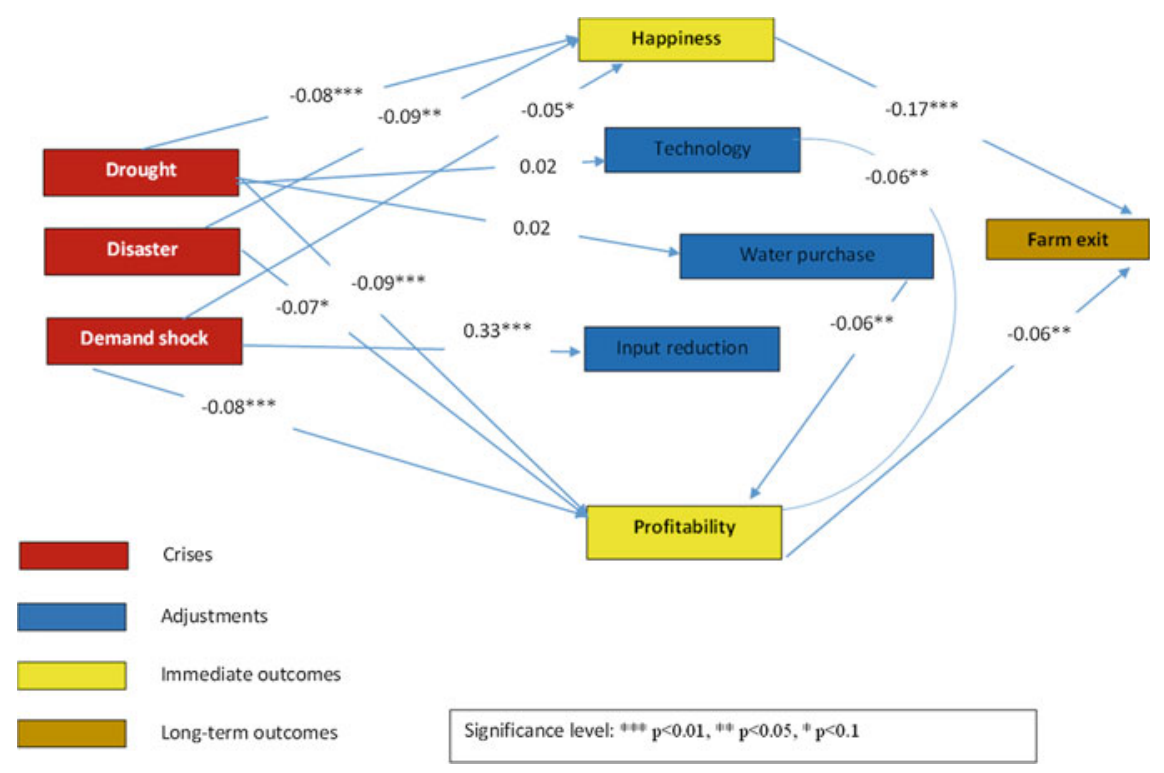

Fig. 3.3 Structural change by profitability and happiness in Australian agriculture (Mann et al. 2017)

\subsection{Residential Choices}

Once you made the decision to take over the farm of your parents, you are usually spared at least one other decision: where to settle down. However, as a reader of this book, you are more likely to face this decision at one or even several stages in your life: Are you looking for a job in a big city or in the countryside? Are you going to move abroad or stay in your country? Will you commute between your home and your work place? The following pages should clarify some of the linkages between this micro-level and the macro-level of regional development.

However, the following subsection will focus on the primary sector and neglect urban issues. Urbanization has been a worldwide trend in the last centuries, as cities, for many people, have apparently become an increasingly attractive option for spending one's lifetime. This trend is partially responsible for the depopulation of peripheral areas. Choosing a clear focus on rural areas with their traditional agricultural character in the context of this volume leads us to the issue of rural development.

For the farming sector, this is important because a sustainable development of rural areas is often cited as one of the reasons to promote or at least keep farming enterprises in peripheral areas which would depopulate and degenerate otherwise. Therefore, the link between the primary sector and rural development should receive special attention over the next pages. 


\subsubsection{The Tiebout Model and Its Limits}

For economic science, the 1950s arguably were a period of significant intellectual development. Robert Samuelson, in 1954, developed a formal definition of public goods. Although it had been clear that certain items would have to be delivered by the government, this mental model clarified under which conditions this should be the case.

The two and a half pages in his 'Pure Theory of Public Expenditure' on which Samuelson laid out these conditions proved to be an important impulse for many scholars to build on these ideas. One of them was Charles Tiebout, then a PhD student at the University of Michigan. He placed an article in the Journal of Political Economy called 'A pure theory of local expenditures' (Tiebout 1956). Whereas Samuelson had mainly been concerned with public goods on the national level, Tiebout thought about goods as being delivered by local authorities. He drew the picture of a well-functioning competition between the local communities in a region or country. There would be towns that would charge high taxes and provide a lot of infrastructure such as good schools, public baths and parks, and there would be towns with lower taxes but without the public amenities. In this model, no need exists for national authorities to interfere because people effectively vote on their feet. If I do not like poor infrastructure, I move to the town with higher taxes, and vice versa.

If this model is taken seriously, there is no need for regional policies. If people find their local development problematic, they are free to move to another region. Peripheral rural counties may die out, but this is how markets work, and likely, people can find regions in other parts of the world that could fit their preferences much better than their present location.

However, research in the last 50 years unearthed much criticism of the Tiebout model, both on theoretical grounds and by empirical experience. These repeated criticisms can be summarized in the following three points:

- Mobility comes at a cost. Although it is possible to move from one community to another, the cost of paying for the moving truck with the furniture is just a minor part of the involved costs. When moving over larger distances, people will have to look for a new job, and the effort to build up a new social network is considerable, particularly for elder people.

- Before moving can begin, costs arise to obtain necessary information. Most countries have thousands of municipalities. It will be impossible to check for all of them (let alone for foreign ones) whether their infrastructure and their local policies suit my needs. Information costs may become prohibitively high.

- Villages need a certain minimum size to finance some necessary infrastructure such as schools, a size that Rieder (1991) estimated as 500 inhabitants for Swiss conditions. At the other end of the spectrum, some economists find that certain megacities have already exceeded an economically reasonable size (Moomaw and Alwosabi 2004). Tiebout, for whom each municipality had an optimal size, had ignored both scenarios. 
These critical voices should not keep us from appreciating Tiebout's contribution to the field: He opened an extremely important debate on how regions should deal with processes of immigration and depopulation. It is likely (as often) that extreme solutions will not lead to an optimal outcome. Neither should artificial infrastructures be established and maintained in regions in which nobody wants to live, nor should we fully trust the market to fix problems and prevent regions from dying out, leaving only the old and vulnerable behind whereas the young have moved to more promising regions.

\subsubsection{Policy and Politics of Rural Development}

Over the last 50 years, policy makers have kept an increasing distance to Tiebout's approach. Both within and outside agricultural policy, the emphasis on rural development in the policy portfolio has certainly increased, particularly in European countries. Mainly two approaches have emerged over recent decades and have been taken by most programs.

For one, it is obvious that not all municipalities, no matter how small, can offer all amenities one could imagine. Nevertheless, it is essential that people can easily access infrastructures such as schools and hospitals, maybe even theatres and swimming pools. To solve this contradiction, policy makers as early as in the 1960s began to focus on a few central locations in problematic regions. In countries with declining population, such as Germany, this 'approach of central locations' helped to prevent outmigration; in countries with high population growth, such as India, it helped transform small towns into vivid growth centres.

The second tool is support for the establishment of enterprises in peripheral regions. Some governments emphasize the relocation of large, existing companies, whereas others see more potential in convincing employed or unemployed people to found their own business.

Such policies, pursued in peripheral areas, may have their origin in two different political frameworks. They may be part of

- General economic policy: Officials in charge of improving entrepreneurship and economic growth may feel responsible for creating instruments designed for poor and peripheral regions.

- Agricultural policy: Officials in this realm may find it too narrow to support just farms for rural development and may want to broaden their support to other sectors.

In some countries, responsibilities have been allocated to one of the two. In other countries, some programs are run by economic and others by agricultural authorities. The latter scenario applies to many regions in the EU. A thorough analysis of such parallel activities was carried out for Switzerland (Mann 2014b), where very similar rural development programs have been in place in parallel for many years, with the economic authorities distributing 30 million Swiss Francs each year and the agricultural authorities 7 million. Actors on the local and national levels were interviewed 
to understand their motivations. On the local level, the analysis identified lack of information exchange as the main problem. Often, actors involved in key positions were not aware that similar programs under a different umbrella would support similar projects. On the national level, actors were much better informed and organized regular exchanges. However, they were careful not to question the equilibrium that policy makers had obtained and were inclined to keep the status quo.

\subsubsection{Turning Points in Village Developments}

To this point, we have only addressed the question of political visions of rural development. Especially peripheral regions clearly need the attention of policy makers, which they actually receive in most countries. There is a public interest, in theory and practice, to keep these areas afloat.

What we still need to discuss is the rural development in the real world. We cannot take for granted that rural development policies will indeed fulfil their promise. To do so, they would have to have an impact on residential choices. The programs would have to influence, directly or more probably indirectly, the decisions of families and individuals where to move or how many children to get. These two variables -migration and birth/death ratios - are the two only instruments having a direct impact on population development.

Usually, population development tends to be extremely stable over long time spans. Geographers have remarked that most regions that have lost inhabitants over the last decades are very likely to do so in the future and vice versa: Areas with increasing population in the past are likely to attract immigrants in the future.

As a first step towards understanding motivations and mechanisms of residential choice, Mann and Gennaio (2011) looked at 10 Swiss villages in which this pattern was disrupted. In five of them, population figures had gone up over decades until, between 1960 and 1990, this development reversed and people emigrated. The other five villages had a clear emigration tradition over decades until, also between 1960 and 1990, people started to move inwards.

A similar analysis could be carried out for cities. For example, Dresden (Germany) and Tallinn (Estonia) both had turning points around the turn of the century, when a negative migration trend reversed into a positive one. However, a city is of course much more complex than a village with a few dozen inhabitants such as Vals in the Swiss Grison Canton. For Vals, it is probably easier to produce a consensus about the reason behind the turning point than for Tallinn.

Well, Vals was perhaps not the best example because it produced somewhat of an outlier reason for its increase in population after a long history of population decline. Residents chose to settle in Vals after a number of companies had invested in this remote mountain location, including a refurbishment of the mineral water factory by Coca Cola Inc. This circumstance was not typical for a village experiencing a positive turning point in its population development. The other four villages in Switzerland-Vorderthal, Doppleschwand, Sant Antonio and Schwändi—portrayed 
a different scenario. Each used to be a farming village with a steadily decreasing number of farms. At a certain point, when urban employees became willing to commute over longer distances, they considered living in these villages and commuting to work. In addition, urban people began migrating into the villages, building houses they would not be able to afford where they worked, and driving to work in the nearby towns each day.

The only similarity between these villages and those with a turning point towards population decline was the existence of one outlier among the five case studies. The outlier in the latter was the small village of Kirchenthurnen, where development was planned on a small piece of land on which construction of new housing should take place. However, a series of bankruptcies prevented the construction projects. Spatial policies in Switzerland did not allow a second piece of land to be converted to building land as long as the first parcel was still available. Here, we can speak of bad luck that entailed a declining number of people in the constant number of houses in the village.

However, the other four cases — Linthal, Andermatt, Airolo and Trun-were probably more interesting from a scientific viewpoint. They used to be either flourishing industrial villages or villages with a large military base. In Linthal and Trun, the downturn of the Swiss textile industry in the second half of the 20th century led to a number of shutdowns and considerable job losses. Who would produce Swiss clothing if trousers and shirts could be imported from China for a fraction of the price? At the same time, the cold war was ending, and military bases in Airolo and Andermatt were reduced considerably. The reduced number of jobs led to a reduced number of residents.

These two sets of stories show some asymmetry. Depopulation could be traced back to structural issues in the local economy. Population boosts, however, could usually not be explained by the local economic performance but rather by the provision of parcels for urban commuters. Economics, after all, might become less important over time to explain rural dynamics, at least in the sense of local production activities.

\subsubsection{Core Factors for Rural Areas}

Case studies are always convenient for an illustration, but larger sample sizes provide much more certainty in terms of general patterns. For this purpose, the population development of villages was analysed econometrically for two regions, namely Switzerland (Mann 2004a; Mann and Erdin 2005) and northeast Germany (Mann 2004b). Thus, some facts are available about the driving forces of residential choices and birth rates.

The studies showed that the number of agricultural jobs had a negative impact on population development in northeast Germany with its few commercial farms. For Switzerland with its many small family farms, the opposite was found. Furthermore, the number of farms (irrespective of their size) in a region was strongly correlated with the region's birth rate. 
These puzzling differences can be explained by the different systems and their different rationales. Northeast German farms used to be greatly overstaffed during socialist times. Since then, an ongoing process of saving on jobs has made regions in which farming played a major role prone to unemployment and subsequent outmigration. In Switzerland, the population level is very stable. However, whereas an average Swiss woman gets 1.4 children over her life span, an average Swiss farmwoman gives birth to 2.7 children. This difference can best be explained by transaction costs. On Swiss family farms, parents spend most of the time engaged in activities where they can supervise their children relatively easily, if compared with 'classical' office careers. Easy child supervision is much less the case on commercial farms of several thousands of hectares in size. Therefore, small-scaled family farming systems have a positive impact on the birth rate.

Another clear difference between the two rural systems is the effect of unemployment. For northeast Germany, we see an expected negative effect of unemployment on population development. The higher the unemployment in rural counties, the higher is the outmigration. In Switzerland, the effect has the opposite direction. In many Swiss regions, unemployment is frictional, i.e. short-term. In these regions, persons entering phases of unemployment do not decide to move away but patiently wait until the next job opportunity in the region opens up. As a result, there may be a positive correlation between unemployment and population growth.

However, when combining economic and non-economic variables into explanatory factors, the predictive value of non-economic factors is stronger than that of economic variables. A high share of people above 65 , combined with a low share of young people, is a powerful predictor of low birth rates. Good accessibility by public transport surprisingly correlates with a negative migration balance. Apparently, trains and buses are mainly used to leave the region rather than to immigrate. The factors summarizing traditional agricultural structures, a high presence of industrial enterprises and a strong presence of the service sector do not have any positive impact on population development. The factors regarding the farming and industrial sectors even have a significant negative impact on the migration balance.

On the municipal level, these relationships imply that we more or less deal with a post-work society. For a rural region, attracting new businesses is partly uncorrelated and partly even negatively correlated with attracting new residents. From a hedonistic viewpoint, it is understandable that neither industrial enterprises nor pig or poultry stables create the most attractive environment for building and inhabiting a new residential home. However, the outlook of villages increasingly having to choose between becoming a production hub or a residential place raises difficult questions for rural development policies. Their focus on attracting businesses may become outdated, and new approaches will have to be identified. 


\subsection{Production and Consumption Choices}

Of all subjects covered in this book, the subject of production and consumption choices is certainly the one with the most literature available. In the many textbooks and articles about farm management, one can find a lot of reflection on which crops to grow and which animals to raise. Regarding consumption, the subject concerned with consumer choices can be distinguished into demand analysis and agricultural marketing. Whereas demand analysis focuses on aggregated data with a particular emphasis on prices, agricultural marketing focuses on the unique characteristics of single products and the best strategies for increasing sales.

This short section will of course not be able to compete which this abundant and inspiring body of literature. We will have to be very selective, focusing within this rather economic topic on subjects with an increased relevance of social factors. In fact, we will focus on the choice to decline possibilities. This section starts by highlighting the organic movement, a movement that decided not to make use of artificial fertilizers and synthetic pesticides. It then proceeds to genetically modified organisms (GMO), or rather to segments of the population choosing not to consume GMO-products. Finally, we will look at consumers opting for non-consumption for other ethical and cultural reasons.

\subsubsection{Organic Production and Consumption}

For centuries, foodstuff on the shelf was distinguishable by the eye, for example apples and pears. One of the arguably biggest innovation brought about by producers and marketers was the use of labels to distinguish identically looking products, such as Golden Delicious apples, depending on whether they were organic or conventional apples. Although brand segregation had existed before, the concept of raw product segregation was born.

Actually, the concept of segregation has two aspects, a technical and a cultural one. It is important to distinguish between these two aspects.

Technical segregation is an engineering-based task, making sure that different product groups, even if visually not different, remain reliably segregated until they reach consumers' refrigerators. Organizational measures have to be established that prevent lower-priced conventional food to be labelled as organic food. In some dairies, for example, first organic milk is bottled, then conventional milk, and then the plant is cleaned. That way, spilling of conventional milk into organic milk is prevented, while spilling of organic milk into conventional milk does not cause any problems. Some organic producer associations do not allow farms to produce partly organically and partly conventionally because they are concerned about technical segregation.

Cultural segregation emphasizes the political and philosophical contents of the organic movement. Many scholars and members of the organic movement have labelled organic production as anti- or post-productivist and as an ecological 
movement against multinational food firms. A typical practical example of cultural segregation is local organic retailers. The decline of their importance in many countries, linked with an increasing coverage of the organic segment by the large international retailers indicates that the importance of cultural segregation is declining. This observation has often been termed the 'conventionalization' of organic farming.

As discussed in the preceding sections, most farms are taken over from the parent generation, and their organic or conventional production status will have followed a 'path-dependency'. Most farmers, at some stage in their career, will consider a system change, even if only for seconds. In fact, an increasing number of farms have changed from organic to conventional production (Sahm et al. 2013), not only in the opposite direction.

Many scholars in the past used the concept of innovation theory to explain the conversion from conventional to organic (e.g. Padel 2001). As already mentioned, the main characteristic of organic farmers is the rejection of certain production factors. Both mineral fertilizer and pesticides have only been available for a - historically_relatively short period. There are many good reasons not to make use of these innovations. However, reasons to view this rejection as an act of particular innovation are rather sparse. Moreover, as the rate of organic farmers starts to exceed $10 \%$ of total farmers in several countries, the concept of innovation theory becomes increasingly less applicable.

Lamine and Bellon (2009) provided a valuable review of the literature on the conversion towards organic farming, distinguishing normative from comprehensive studies and studies concerned with the short time of conversion itself from studies taking into account the longer process of preparation and adaptation. They see a particular lack of attention to this latter point, as few social scientists have taken the time to observe long-time processes of transformation.

This point is very important because the farms switching from one system to another only represent a certain group of farmers, termed 'optimizers' by Mann and Gairing (2012). Usually, these converters use their production system as a tool to generate a decent income. Farmers remaining in their system-be it organic or conventional - are very loyal to their current system. A large number of conventional farmers would never consider converting to organic production, and many organic farmers cannot imagine allowing conventional production factors on their farms.

This distinction between 'loyals' and optimizers can also be made for consumers. Nevertheless, the number of consumers who never eat any organic food is small in most developed countries, and even smaller is the number of consumers who never eat anything that is conventionally grown. In fact, for consumers, 'optimizing' is the usual behaviour. In this process, some kind of selectivity can be observed: We find more consumers choosing organic lemons and carrots but conventional beer and chocolate than consumers choosing the opposite.

A Swiss study (Götze et al. 2016) showed that consumers have fixed patterns regarding what products they preferably buy in organic quality. Most importantly, the stronger the degree of processing the lower is the share of organic food. This choice is not rational because both the health-related and the environmental effects of organic compared with conventional food do not depend on the degree of processing. 
It shows that our intentions are different when we buy raw produce as compared with our purchases of ready-made pizza.

Another finding was that the market share of organic products is higher for imported foodstuff than for domestically produced farm outputs. This choice is more rational than the one just described. Apparently, the organic label serves as a guarantee for certain production standards, as consumers may know that legal standards differ considerably from (exporting) country to country.

Organic farming is not gender neutral. Among the relatively few female farmers in western countries, the share of organic farmers is always higher than among male farmers, as for example Jacobson et al. (2003) showed for Florida and Bjorkhaug (2006) for Norway. The same can be said about the consumers. All analyses of consumption data show that women are much more likely to purchase organic qualities than are men, from Australia (Lockie et al. 2002) to Ireland (Davies et al. 1995).

The level of education also influences producers and consumers similarly in their preference for organic agriculture. Most studies find that 'regular consumers tend to be educated' (Padel and Foster 2006: 606), and studies on the adoption of organic farming find that better educated farmers produce organically more often than less educated farmers (e.g. Mzoughi 2011). Again, education works symmetrically on the production and consumption side.

The idea that producers and consumers of organic food share not only common values but also social characteristics is not new (Storstad and Bjorkhaug 2003). However, in recent years sufficient evidence has accumulated: Producers and consumers of organic food constitute an influential social group. The social aspect may very well be a significant driver in the success of organic farming. Hundreds of production systems have been promoted, including integrated production or animal-friendly production. Nonetheless, only organic farming, relying on a few simple rules, has been able to establish in almost all countries in the world and to obtain a high degree of public attention.

\subsubsection{Genetically Modified Organisms}

After scientists had made technical advances in agriculture, a segment of consumers decided they would not want to take advantage of them, and a segment of producers decided the same. This plot sounds familiar from the preceding subsection on organic farming, and it seems to duplicate itself in the story of genetically modified (GM) crops. Thus, we deem it worthwhile to examine both the parallels and the differences between the two stories.

The time dimension is certainly among the strongest differences. Artificial fertilizers were synthesized in the 19th century, and synthetic pesticides started their career in the early 20th century. Genetic modification, however, became possible from around 1980 onwards.

Another difference is the extent of proven harm the technologies have been causing. The US Fish and Wildlife Service estimates that 72 million birds are killed by 
pesticides in the US each year. Fatalities for humans are certainly lower, but worldwide deaths and chronic diseases may reach one million per year. GMO certainly do not reach this extent of acute damage. However, the opponents of GMO raise three major points against working with modified seeds:

- About $80 \%$ of GM crops have herbicide resistance as their innovative characteristic. This means that the main impact of GMO is the increased usage of total herbicides. The 'Non-GMO Project' argues that the use of total herbicides like Roundup has increased by the factor 15 since GMO came on the market.

- For pesticides, some detrimental long-term effects only became visible decades after usage. It still can be argued that negative long-term effects of GMO (be it on human health or the environment) may not be visible yet, although this argument loses weight over time.

- GMO-technology requires major investments in infrastructure and knowledge. This is an advantage for multinational companies like Monsanto and Syngenta and prevents their use for minor breeding companies. Therefore, the use of GMOtechnology has implications for the seed industry's structure.

These (and other) reservations against GMO have led a number of countries such as Russia, Peru, Venezuela or Austria to ban the use of GMO in agriculture and even imports of GMO-produced food and feed. Other countries such as Germany and France also do not allow cultivation but tolerate imports. This is another significant distinction to the organic market, where no government has banned the cultivation of conventional crops or the import of conventional food products. The reason for this difference cannot be the harm caused by GMO — or conventional production but more likely lies in the benefits. Few governments would like to impair the productivity that artificial fertilizers and synthetic pesticides have brought to their agriculture, which would be the consequence of banning conventional agriculture. Compared with this scenario, the costs of banning herbicide-resistant GM crop varieties are relatively low.

There is also a political reason that would speak for banning GMO, at least for European administrations. According to a 'Eurobarometer' in 2010, 59\% of Europeans believe that GM food is not safe for their health. This high degree of scepticism leads us to the question of labelling. If food containing GMO is sold, should consumers be made aware of it?

Two agricultural economists from Greece developed a model after their emigration to the US showing that labelling brings advantages. Their model, as shown in Fig. 3.4, sorts consumers in relation to their attitude towards artificial technologies. On the very left, you find consumers indifferent to how their food was produced. On the very right, consumers are opposed to any kind of artificial inputs and have a high preference for organic food.

In the reference scenario, there is no labelling of GM food. The net utility for eating non-labelled (nl) food is defined by the gross utility $(\mathrm{U})$ and the food's price $\left(\mathrm{p}_{\mathrm{nl}}\right)$, as is the utility of eating organic (o) food, which depends on $U$ and $p_{o}$. Predictably, the $\mathrm{x}_{\mathrm{nl}}$ segment on the left derives higher utility from eating non-labelled food, whereas 


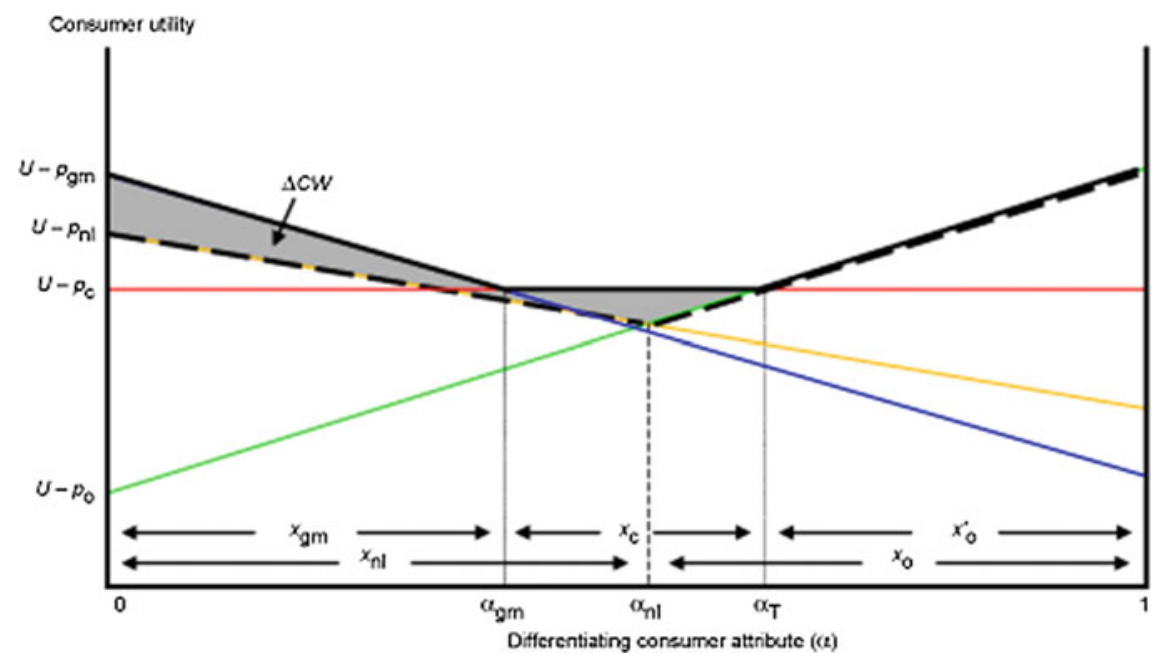

Fig. 3.4 Market and welfare effects of mandatory labelling of genetically modified products (Giannakas and Yiannaka 2006)

the $\mathrm{x}_{\mathrm{o}}$ segment right of $\alpha_{\mathrm{nl}}$ will choose organic food because utility is higher than when consuming the non-labelled food.

After mandatory labelling, consumers can distinguish between GM food with a net utility of $\mathrm{U}-\mathrm{p}_{\mathrm{gm}}$ and conventional (c) food with a net utility of $\mathrm{U}-\mathrm{p}_{\mathrm{c}}$. Figure 3.4 shows how this scenario affects market shares: Organic food actually loses market shares as only the $x^{\prime}{ }_{0}$ segment still relies on organic food. Between the extremes, there is a segment $x_{c}$ that purchases conventional food, whereas the $x_{g m}$ segment buying GM food is able to cut costs by buying labelled GM food. This effect of cost saving and the benefit of being sure that the food does not contain GMO causes the two grey areas, which represent the positive consumer welfare effect $(\Delta \mathrm{CW})$ of mandatory GMO-labelling in the model. This model neglects, of course, transaction costs, which are always on the negative side of mandatory labelling.

Whereas this model treats labelling of GM food as an either-or issue, the reality is-as usual-more complex. In Germany, for example, labelling is mandatory if food contains parts of GM crops (almost non-existent on the German food market). However, labelling is not mandatory for animal products that were produced with GM feed, and these products are very common.

In milk, for example, traces of GM feed used during production may not be detectable. Nevertheless, there is a demand among consumers for milk produced without GM feed. As no mandatory labelling exists for this kind of milk, some producers use negative labelling to advertise milk that was produced without GM feed. This market segment for 'GMO-free milk' can be divided into three parts: 
- Because organic production outlaws GM feed, the market for organic milk is also a market for GMO-free milk. Producers of organic milk receive a premium of around 8 Cents per litre.

- Some dairies use the label 'ohne Gentechnik' (without GMO) and contract farmers who do not use GM feed. To these farmers, they pay a premium of 0.3 to 1 Cents per litre.

- Other labels like Haymilk or fair milk link GMO-free feed with some other environmental or social attributes, usually paying premiums between the two figures above.

This overview indicates that the attribute 'GMO-free' has not at all attained a similarly convincing power as the organic label. However, market niches have been created.

It is worthwhile to compare the outlined German approach with the Swiss one. The legal situation in this adjacent country is the same: It is legally possible to import GM feed, although the cultivation of GM crops is not allowed. However, market partners in Switzerland stopped importing GM soybeans in 2007, after a blackmailing campaign by Greenpeace. Since that time, Swiss feed importers have shouldered some effort and additional costs to import GMO-free soybeans, mostly from Brazil. Of course, from a welfare-oriented point of view, this strategy causes losses for consumers who face higher-than-necessary milk prices if they do not prefer GMO-free milk.

The global market for soybeans and corn (by far the two economically most important GM species) shows that technical segregation can occur on three levels:

- We find countries (such as Switzerland) that segregate on a national level by excluding GM feed, but a larger number of countries have a market for GM feed plainly because there is no demand for GMO-free qualities. Portugal would be one example.

- Segregation can also take place within a company. Some logistic enterprises, for example, have trucks they use for GM feed and others they use for GMO-free qualities.

- The most frequent level of segregation, however, is the company. Particularly multinational companies such as Cargill and Bunge offer only GM qualities, whereas slightly smaller companies such as ACTI and COFCO often offer exclusively GMO-free qualities.

The theoretical model depicted in Fig. 3.5 may explain why the company as segregation level is chosen so often. The more centrally segregation is carried out the higher are frustration costs. This scenario applies, for example, to Swiss consumers who would like to buy milk containing GMO if they can save a few Cents by doing so. The technical costs, however, are high if segregation is carried out within companies. Likely, minimum total costs occur at a level $\left(\mathrm{L}_{\min }\right)$ between these extreme solutions. 
Fig. 3.5 The costs of technical segregation (Mann 2015a, b)

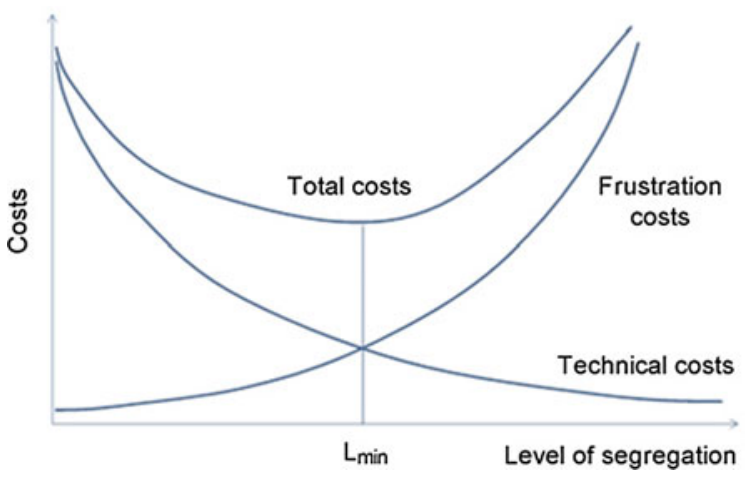

\subsubsection{More on Non-consumption}

So far, we have shown that concerns for the environment or for one's health can be reasons to forgo certain consumption options such as conventional or GM food. However, a growing number of people renounce meat (and often fish) consumption neither for health nor for environmental reasons. They consider it as wrong to kill animals for the purpose of eating them and thus choose to eat a vegetarian diet.

The best country to study vegetarianism is certainly India, where 30 to $40 \%$ of the people do not eat meat. The 360 million vegetarians in India probably outnumber vegetarians in the rest of the world. The reason for this unique situation is religion. It would be an undue simplification to say that Hinduism prescribes vegetarian diets, but the least one can say is that Hindus pursue a particularly complex relation between caste, class, gender, kinship and meat consumption. Fischer (2016) nicely illustrated how this social acceptance of vegetarian diets relates to food markets. It had led, for example, to labels for vegetarian products and unusual product portfolios of otherwise standardized fast-food chains such as McDonalds.

If consumers do not want animals to die for them, vegetarian diets that contain eggs and milk may not do the job. More often than not, the fate of male chicks in egg production and of male calves in milk production is not apt to high ethical standards. Therefore, proponents of vegan lifestyles (where you avoid any product of animal origin) certainly have a strong argument to make. However, although vegan products are among the fastest growing segments on the food market, people who eat strictly vegan diets still represent less than $1 \%$ of the population in most countries.

An obstacle to measuring the share of vegetarian, vegan and even organic diets is methodology. Sociologists are aware that respondents to surveys do not necessarily tell the truth but like to tell things they expect society to appreciate, a motivation called 'social expectancy'. An illustrative example is organic food, for which the share of organic products bought according to surveys was around $20 \%$ in Germany at times when the real market share was around 2\% (Simons et al. 2001). For vegetarian and vegan diets, 'market shares' are much more difficult to measure. It is likely that not all of the $13 \%$ of Swiss people stating vegetarian diets in a survey are indeed vegetarian. 
An analysis of the purchasing behaviour of households over one month showed the share of vegetarian households in Switzerland to be below 5\%. Nevertheless, many Swiss consumers have concerns about the ethical justification of eating meat, although they are not able or willing to switch to a vegetarian or even vegan diet (Berndsen and van der Pligt 2004).

Hinduism, by the way, is not the only religion that supports vegetarianism. In Christianity, vegetarian diets were prescribed for centuries in the weeks before Easter. In most Christian countries, this habit has been fading. Today, forgoing chocolate or alcohol, if anything at all, has become as popular as forgoing meat. In Romania, however, a significant part of the population still follows the 'Lent' practices of the Orthodox Church. This practice forbids the consumption of any animal product with only very few exceptions and of alcohol. In recent years, while Romanians have gained some material wealth when compared to either the dire years of socialism or the difficult period of political-economic transformation, the practice of fasting gains some attractiveness again - the share of households not consuming alcohol and animal products during Lent is rising.

\section{References}

Berndsen M, van der Pligt J (2004) Ambivalence towards meat. Appetite 42(1):71-78

Besser T, Mann S (2015) Which farm characteristics influence work satisfaction? An analysis in two agricultural systems. Agric Syst 141:107-112

Bjorkhaug H (2006) Is there a female principle in organic farming? In: G. Holt, M. Reed (eds) Sociological perspectives on organic agriculture. CAB International, Wallingford

Briggemann BC (2011) The importance of off-farm income to servicing farm debt. Federal Reserve Bank of Kansas City. Econ Rev (First Quarter):63-82

Calabrese C, Mann S, Dumondel M (2012) Patterns of occupational choice in the Swiss alpine labor market. Yearb Socioecon Agric 2012:31-54

Calabrese C, Mann S, Dumondel M (2014) Alpine farming in Switzerland: discerning a lifestyledriven labor supply. Rev Social Econ 72(2):137-156

Corrado A, de Castro C, Perrotta D (2017) Cheap food, cheap labour, high profits: agriculture and mobility in the Mediterranean. In: Corrado A., de Castro C, Perrotta D (eds) Migration and agriculture. Routledge, London

Davies A, Titterington AJ, Cochrane C (1995) Who buys organic food? A profile of the purchasers of organic food in Northern Ireland. British Food J 97(10):17-23

Fischer J (2016) Markets, religion, regulation: Kosher, halal and Hindu vegetarianism in global perspective. Geoforum 69(1):67-70

Giannakas K, Yiannaka A (2006) Agricultural biotechnology and organic agriculture: national organic standards and labeling of GM products. AgBioForum 9(2):3

Götze F, Mann S, Ferjani A, Kohler A, Heckelei T (2016) Explaining market shares of organic food: evidence from Swiss household data. Br Food J 118(4):931-945

Jacobson SK, Sieving KE, Jones GA, Van Doorn A (2003) Assessment of farmer attitudes and behavioral intentions toward bird conservation on organic and conventional Florida farms. Conserv Biol 17(2):595-606

Keating NC, Little HM (2007) Choosing the successor in New Zealand family farms. Family Bus Rev 10(2):157-171 
Kimhi A (2000) Is part-time farming really a step in the way out of agricultural? Am J Agr Econ 82(1):38-48

Lamine C, Bellon S (2009) Conversion to organic farming: a multidimensional research object at the crossroads of agricultural and social sciences. A review. Agron Sustain Dev 29(1):97-112

Lockie S, Lyons K, Lawrence G, Mummery K (2002) Eating 'Green': motivations behind organic food consumption in Australia. Sociologia Ruralis 42(1):23-40

Lowder SK, Skoet J, Raney T (2016) The number, size, and distribution of farms, smallholder farms, and family farms worldwide. World Dev 87(4):16-29

Mann S (2004a) Landwirtschaft und ländlicher Raum. Agrarforschung 11(2):44-49

Mann S (2004b) Die Entsiedelung ländlicher Räume und das Agrarsystem. Berliner Debatte INITIAL 15(2):46-55

Mann S (2007a) Tracing the process of becoming a farm successor on Swiss family farms. Agric Hum Values 24(4):435-443

Mann S (2007b) Zur Produktivität der Nebenerwerbslandwirtschaft in der Schweiz. Agrarforschung 14(8):344-349

Mann S (2014a) Individual utility effects of minimum wages in a new activity-choice framework. Forum Social Econ. https://doi.org/10.1080/07360932.2014.946944

Mann S (2014b) Understanding parallel structures in public administration. Int J Org Theory Behav 17(3):275-292

Mann S (2015a) Deconstructing agricultural labour: a reflection on negative farm income. J SocioEcon Agric 8:70-75

Mann S (2015b) Is "GMO Free" an additional "Organic"? On the economics of Chain segregation. AgBioForum 18(1):4

Mann S, Erdin D (2005) Die Landwirtschaft und andere Einflussgrössen auf die Bevölkerungsentwicklung im ländlichen Raum. Agrarwirtschaft 54(5):258-264

Mann S, Freyens B, Dinh H (2017) Crises and structural change in australian agriculture. Rev Social Econ (accepted)

Mann S, Gairing M (2012) 'Loyals' and 'Optimizers'—shedding light on the decision for or against organic agriculture among Swiss farmers. J Agric Environ Ethics 25(3):365-376

Mann S, Gennaio M-P (2011) Wendepunkte in der Dorfentwicklung. ART-Schriftenreihe, Bd, Tänikon, p 16

Mittenzwei K, Mann S (2017) The rationale of part-time farming: Empirical evidence from Norway. Int J Social Econ 44(1):53-59

Moomaw RL, Awusabi MA (2004) An empirical analysis of competing explanations of urban primacy evidence from Asia and the Americas. Ann Reg Sci 38(1):149-171

Mzoughi N (2011) Farmers adoption of integrated crop protection and organic farming: do moral and social concerns matter? Ecol Econ 78(8):1536-1545

Padel S (2001) Conversion to organic farming: A typical example of the diffusion of an innovation? Sociologia Ruralis 41(1):40-61

Padel S, Foster C (2006) Exploring the gap between attitudes and behaviour: Understanding why consumers buy or do not buy organic food. Br Food J 107(8):606-625

Pagano U (1985) Work and welfare in economic theory. Basil Blackwell, Oxford

Perry N, Reybold LE, Waters N (2014) ‘Everybody was looking for a good government job’ occupational choice during segregation in Arlington, Virginia. J Urban Hist 40(4):1-23

Pierson R (1978) What about the farm workers. J Agric Econ 29(3):233-242

Rieder P (1991) Die Erhaltung der bäuerlichen Kulturlandschaft der Alpen. http://e-collection. library.ethz.ch/eserv/eth:49257/eth-49257-01.pdf (June 14, 2017)

Rosen S (1986) The theory of equalizing differences. In: Ashenfelter O, Layard R (eds) Handbook of labor economics, vol I. Amsterdam, Elsevier

Sahm H, Sanders J, Nieberg H, Behrens G (2013) Reversion from organic to conventional agriculture: a review. Renew Agric Food Syst 28(3):263-275 
Saverio Caruso, F. (2016): Unionism of migrant farm workers. In A. Corrado, C. de Castro, D. Perrotta: Migration and Agriculture: Mobility and change in the Mediterranean area. London: Routledge

Simons J, Vierboom C, Härlen I (2001) Einfluss des Images von Bio-Produkten auf den Absatz der Erzeugnisse. Agrarwirtschaft 50(5):286-293

Storstad O, Bjorkhaug H (2003) Foundations of production and consumption of organic food in Norway: common attitudes among farmers and consumers? Agric Hum Values 20(2):151-163

Tiebout C (1956) A pure theory of local expenditures. J Political Econ 64(5):416-424

Tzouramani I, Alexopoulos G, Kostianis G, Kazakopoulos L (2014) Exploring risk management strategies for organic farmers: a Greek case study. Renewable Agric Food Syst 29(2):167-175

Zhao Y (1999) Labor migration and earnings differences: the case of rural China. Econ Dev Cult Change 47(4):767-782

Open Access This chapter is licensed under the terms of the Creative Commons Attribution 4.0 International License (http://creativecommons.org/licenses/by/4.0/), which permits use, sharing, adaptation, distribution and reproduction in any medium or format, as long as you give appropriate credit to the original author(s) and the source, provide a link to the Creative Commons license and indicate if changes were made.

The images or other third party material in this chapter are included in the chapter's Creative Commons license, unless indicated otherwise in a credit line to the material. If material is not included in the chapter's Creative Commons license and your intended use is not permitted by statutory regulation or exceeds the permitted use, you will need to obtain permission directly from the copyright holder.

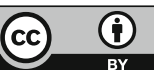

